\title{
PAISAGEM E TURISTIFICAÇÃO: ESTUDO DE CASO EM CANOA QUEBRADA E MAJORLÂNDIA, CE, BRASIL.
}

\author{
Roberto Sakamoto Rezende de Souza ${ }^{1}$
}

\begin{abstract}
RESUMO: O presente artigo tem como proposta uma análise do processo de turistificação e suas implicações na transformação da paisagem de localidades turísticas litorâneas no Brasil, através de um estudo de caso na região do município de Aracati, no Ceará. Peguntamo-nos inicialmente qual o motivo de Canoa Quebrada ser o destino turístico mais estruturado, e, portanto, preferido pelos turistas que procuram a região. Propõe-se como ponto de partida para a pesquisa a investigação do discurso das fontes oficiais de informação sobre o processo de desenvolvimento turístico da região e o seu confrontamento com observações realizadas em visita de campo.
\end{abstract}

PALAVRAS-CHAVE: Paisagem. Turistificação. Canoa Quebrada.

\section{LANDSCAPE AND TOURISTIFICATION: CASE STUDY IN CANOA QUEBRADA AND MAJORLÂNDIA,CE, BRASIL.}

ABSTRACT: This article presents an analysis of the touristification's process and its implications on the transformation of touristic locations on the Brazilian coast, through a case study that took place in Aracari, located in the state of Ceará. Initially, we wondered what was the reason that made Canoa Quebrada be the most structured touristic destination and, therefore, becoming the tourists' favorite destination in the region. It was proposed as a starting point for research the investigation of information official sources' speeches on the touristic development process in the region and its confrontation with observation during site visits.

\section{PAISAJE Y TURISTIFICACIÓN: ESTUDIO DE CASO EN CANOA QUEBRADA Y MAJORLÂNDIA, CE, BRASIL.}

RESUMEN: El presente artículo tiene como propuesta un análisis del proceso de "turistificación" y sus implicaciones en la transformación del paisaje de asentamientos turísticos costeros en Brasil, a través de un estudio de caso en la región del municipio de Aracati, en el Estado de Ceará. Inicialmente nos preguntamos cual es la razón de por qué Canoa Quebrada se configura como el destino turístico más consolidado en cuanto a infraestructura y servicios y, por lo tanto, preferido por los turistas que buscan la región. Se propone como punto de partida para la investigación el desarrollo de un marco teórico conformado por diversas fuentes oficiales de información sobre el proceso de desarrollo turístico de la región y su confrontación con observaciones realizadas en visita a terreno.

\footnotetext{
${ }^{1}$ Doutorando da área de concentração Paisagem e Ambiente, Faculdade de Arquitetura e Urbanismo da Universidade de São Paulo. robertosakamoto@gmail.com.
}

Revista Científica ANAP Zrasd, v. 8, n. 11, 2015, p. 63-78. 


\section{ANAP $B_{\text {rasil }}$ \\ ISSN 1904-3240 \\ V. 8, n. 11}

\section{INTRODUÇÃO}

O presente artigo tem como proposta uma análise do processo de turistificação e suas implicações na transformação da paisagem de localidades turísticas litorâneas no Brasil, através de um estudo de caso na região do município de Aracati, no Ceará. Nesse contexto, observamos o processo recente ocorrido na localidades de Canoa Quebrada e Majorlândia, pertencentes ao município de Aracati-CE. Peguntamo-nos inicialmente qual o motivo de Canoa Quebrada ser o destino turístico mais estruturado, e, portanto, preferido pelos turistas que procuram a região.

\section{OBJETIVOS}

Pretendemos neste trabalho analisar o processo de turistificação das localidades estudadas sob a ótica da transformação da paisagem pelos processos de urbanização. Para alguns autores como ALMEIDA e KOROSSY (KOROSSY 2012), o processo de turistificação pode ser descrito como o momento em que os territórios são destinados a atender às satisfações dos que chegam de fora. "o processo de apropriação do lugar para e pelo turismo"(ALMEIDA apud KOROSSY 2012), ou o "processo de transformação de um determinado território em um território turístico e as consequentes alterações que este processo impõe na estrutura espacial e na sociedade." (KOROSSY op. cit) Para BRITTO HENRIQUES (BRITO HENRIQUES apud KOROSSY op. cit): turismo é na sua essência um fenômeno eminentemente urbano. A urbanização gera turismo, e o turismo induz à urbanização.

Para MACEDO, o processo de transformação da paisagem litorânea pelo turismo é conhecido e se desenvolve em etapas que se inicia de uma fase de descoberta de um "paraíso intocado", passando pela consolidação no imaginário turístico do local como "Éden", até a transformação total da paisagem local com a perda da paisagem "rústica" e a implantação de loteamentos convencionais e infraestrutura. (MACEDO 1993, p. 71) 


\section{ANAP $B_{r a s i}$ \\ ISSN 1904-3240 \\ V. 8, n. 11}

\section{MÉTODO DE ANÁLISE}

Propõe-se como ponto de partida para a pesquisa a investigação do discurso das fontes oficiais de informação sobre 0 processo de desenvolvimento turístico da região, captado em publicações do Governo Federal (Ministério do Turismo), Governo Estadual (Secretaria de Turismo), Associação de Empreendedores de Canoa Quebrada, teses e dissertações de pesquisadores ligados ao turismo e meio ambiente. Em seguida pontuamos as observações feitas em campo, confrontando estas com o discurso oficial.

\section{RESULTADOS}

Caracterização: município de Aracati

Localizado no litoral leste do Estado, o município de Aracati faz parte do Polo Litoral Leste, articulação definida pela Secetaria de Turismo do Estado do Ceará - SETUR. Fundado em 1603 como um povoado situado à margem do rio Jaguaribe, Aracati teve grande importância econômica regional, chegando a concorrer com Fortaleza desde 1726. O declínio da economia baseada na pecuária, o crescimento da produção de algodão e as limitações das condições portuárias conduziram a cidade à estagnação já no final do século XVIII. (DANTAS 2003 p. 64)

A Praia de Canoa Quebrada é uma localidade pertencente ao município de Aracati - CE, distante $160 \mathrm{~km}$ de Fortaleza, e é considerada o primitivo destino turístico do Ceará, para onde os primeiros viajantes se deslocavam na década de 1970 em busca das belezas naturais ditas "intocadas" ali encontradas. (SETUR 2011a, ASDECQ 2013). 


\section{ANAP

\section{REVISTA C I EN TIF I CA 2015}

Figura 1. Localização de Canoa Quebrada em relação a Fortaleza-CE.

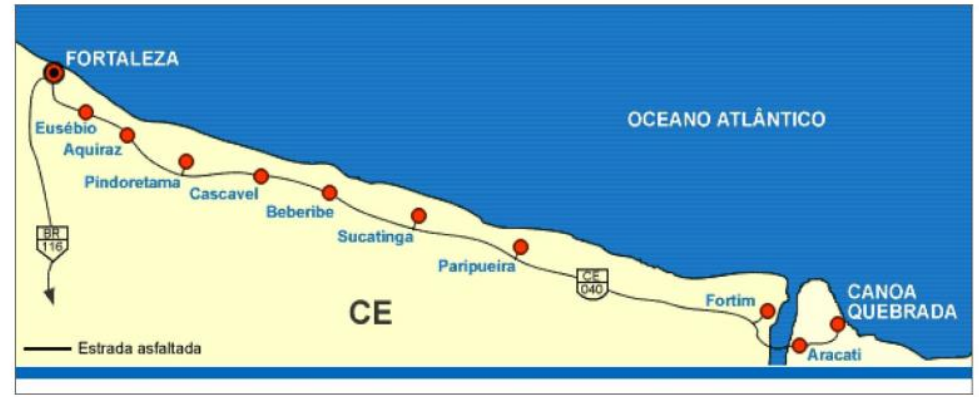

Fonte: DANTAS 2003.

O município de Aracati possui um dentre os 65 destinos indutores do desenvolvimento turístico regional selecionados no Brasil pelo Ministério do Turismo. Destes, 23 estão na região Nordeste sendo quatro no Ceará. São eles Aracati (Canoa Quebrada), Jijoca (praia de Jericoacoara), Fortaleza e Nova Olinda (Cariri).

Segundo a tradição popular, conta-se que o nome Canoa Quebrada surgiu como referência ao naufrágio do navio português de Francisco Aires da Cunha, naquela localidade em 1650. "O capitão Francisco Aires da Cunha vinha de Portugal com a finalidade de fundar povoados no litoral do Brasil, indo à procura de Jerônimo de Albuquerque, fundados de Natal. Saindo de Natal, o capitão foi ao encontro de Martins Soares Moreno, quando seu barco chocouse (sic) em uma pedra e, mesmo avariado, procurou a enseada onde fica 0 núcleo de Canoa Quebrada, em Aracati. Os moradores de Aracati, que não conheciam embarcações além de canoas e jangadas, diziam 'vamos ver a canoa quebrada na beira da praia'"(DANTAS, 2003)

Até o final dos anos 1970, as principais atividades de Canoa Quebrada eram a pesca artesanal e a confecção de uma renda característica da região denominada 'labirinto'. O excedente da produção era comercializado com Aracati, de onde eram adquiridos outros elementos de consumo. Em meados da década de 1970 a comunidade foi descoberta por "jovens do movimento de contestação pós anos 60 , iniciado na juventude americana e europeia, que se 


\section{ANAP $B_{\text {rasil }}$ \\ ISSN 1904-3240 \\ V. 8, n. 11}

expandiu por todo o mundo, o chamado movimento hippie. (...) é nessa busca de um espaço idealizado que Canoa Quebrada foi descoberta e transformada num sonhado 'paraíso'." (CIRINO apud DANTAS 2003)

DANTAS aborda este início de processo turístico com certo romantismo, afirmando que a relação que se desenvolveu entre nativos e forasteiros "foi de plena harmonia e não teve nenhum caráter de exclusão. A hospedagem era de graça e se dava no próprio espaço familiar e os laços de amizade que surgiram foram grandes. (...) Muitos nativos, até hoje, demonstram um certo orgulho por terem acolhido os primeiros visitantes em Canoa." A autora descreve o processo de urbanização desenfreado que ocorreu durante a década de 1980, quando o interesse econômico surgido com o turismo motivou a construção de uma estrada de acesso. A estrada foi um grande benefício para a comunidade, bem como ocasionou um afluxo ainda maior de turistas, alimentando um ciclo de crescimento sem planejamento, com graves consequências sociais, ambientais e paisagísticas. $O$ processo não é incomum e foi descrito em outras localidades litorâneas com muitas semelhanças, como Mosqueiro em Belém do Pará (NÓBREGA 2009), Bertioga-SP (SOUZA 2007) e Ponta da Tulha em Ilhéus-BA (SENA e QUEIROZ 2009)

Atualmente, Canoa Quebrada é um dos destinos turísticos mais procurados do Ceará, juntamente com a capital Fortaleza e resorts como o Beach Park em Aquiraz. (SETUR 2011a) Como parte das estratégias para o fomento do turismo na região está a adequação do aeroporto de Aracati para a operação de voos comerciais, já anunciada pelo Ministério do Turismo2.

\footnotetext{
${ }^{2}$ http://www.turismo.gov.br/component/content/article.html?id=5236 acesso em 10-7-2015
} 


\section{ANAP

\section{REVISTA C I EN TIIFICA 2015}

Figura 2. Mapa de Canoa Quebrada.

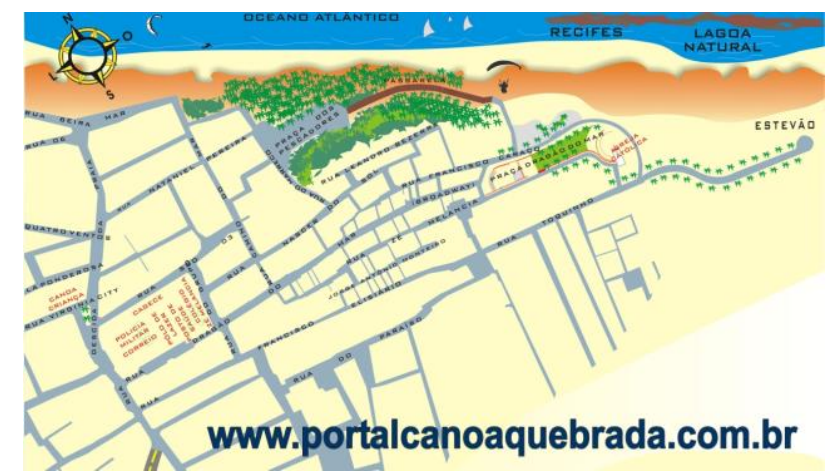

Fonte: portalcanoaquebrada.com.br. Acesso em julho 2015

Turismo internacional

O destino é tido pela SETUR como de atratividade internacional. Conforme dados da Secretaria de Turismo do Ceará, "o principal emissor de turistas estrangeiros para o estado é a Itália (28\% em 2009), seguida por Portugal (14\%), França (8\%) e Estado Unidos (6\%). Já em relação aos turistas domésticos recebidos pelo estado, predominam aqueles procedentes da região Sudeste e, em seguida, da região Nordeste. De acordo com a SETUR-CE, os principais estados emissores são: São Paulo (25\% do fluxo em 2009), Distrito Federal (10,1\%) e Rio de Janeiro (10\%). "(SETUR op. cit)

Turismo e infraestrutura

A melhoria no acesso aeroviário parece ter prioridade na agenda de investimentos em relação a melhoramentos na coleta de resíduos sólidos e saneamento. Segundo o IBGE (IBGE 2008 apud SETUR 2011b), o município de Aracati possui 1,81\% dos domicílios com coleta de esgoto, enquanto Canoa Quebrada, em melhores condições, apresentava em 2001 17,3\% dos domicílios com o serviço. (Secretaria Municipal de Saúde de Aracati 2001 apud DANTAS 2003 p. 109)

Segundo a SETUR,

O serviço de coleta de lixo é realizado diariamente e atende a totalidade da população; todo resíduo sólido coletado no município é depositado em lixões a céu aberto. O município ainda não dispõe de 


\section{ANAP

métodos de coleta e disposição dos resíduos que garantam a sustentabilidade ambiental de sua área, o que se faz de extrema importância, já que o turismo utiliza majoritariamente os recursos naturais locais. (...) A construção de um aterro sanitário no município está prevista e, inclusive, compõe a matriz de investimento do Prodetur III no estado do Ceará. A área destinada ao aterro está localizada próxima ao Aeroporto Regional de Aracati, na rota das aeronaves, motivo pelo qual estão em estudo áreas alternativas para implantação da obra. (SETUR 2011b).

Figura 3. Coleta de lixo em Canoa Quebrada.

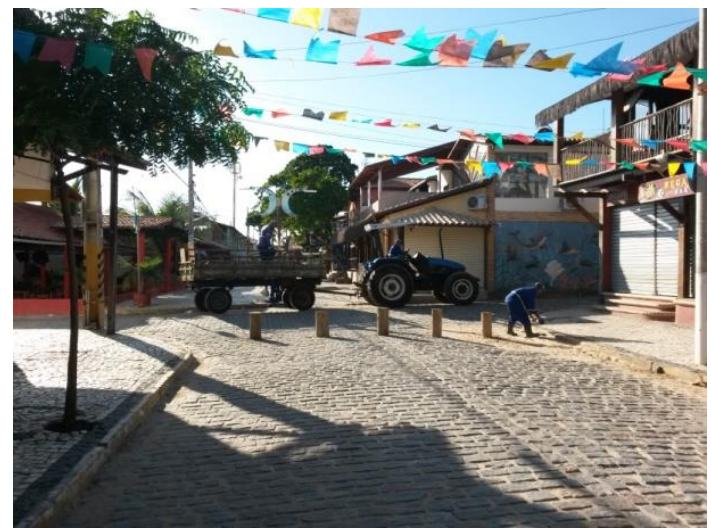

Tabela 21. Sistema de abastecimento de água - Aracat

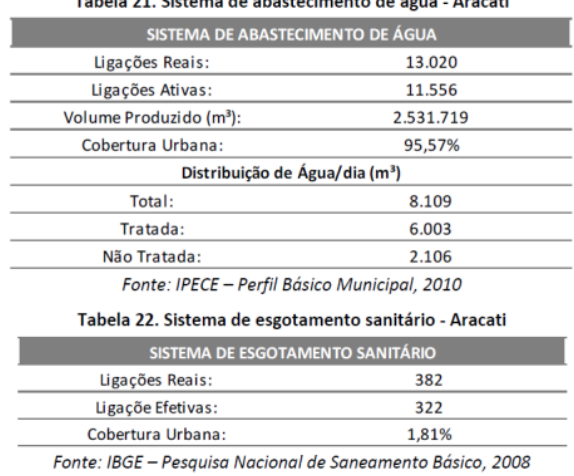

Fonte: Roberto Sakamoto 2015.

\section{Perfil do turista \\ Conforme dados da SETUR-CE,}

a maior parcela dos visitantes do estado é composta por pessoas na faixa etária dos 26 aos 50 anos. Trata-se, em geral, de um público majoritariamente adulto, porém, que ainda não chegou à terceira idade. A maior parte destes turistas tem o Ensino Superior completo,. (...) A grande maioria dos turistas que viajou ao Ceará a lazer em 2009 teve nos atrativos naturais do estado o principal fator determinante de sua visita (mais de $90 \%$ ). Nestes atrativos naturais estão englobados tanto aqueles relacionados a sol e praia, como ao ecoturismo e turismo de aventura. (SETUR op. cit)

Segundo o Ministério do Turismo, em 2013 o Estado do Ceará possuía 346 estabelecimentos hoteleiros com 29.069 leitos, $13,2 \%$ de um total de 219.765 leitos da região Nordeste. O município de Aracati possuía 3000 leitos em 2012. (SETUR 2014) 


\title{
ANAP

\section{A Associação Comercial de Canoa Quebrada \\ O romantismo também é percebido no discurso da Associação dos} Empreendedores de Canoa Quebrada - ASDECQ. Na única edição publicada da revista " $Q$ Canoa", o discurso passa do sugestivo ao imperativo, como que ordenando ao turista o que ele deve ver e consumir.

Canoa Quebrada oferece uma variedade de atrativos para seus visitantes. No primeiro dia de estadia, logo pela manhã é recomendado começar pelo símbolo de lua e estrela esculpido na falésia e caminhar pela maré baixa se você quiser um refrescante mergulho nas piscinas naturais que se formam frente ao Estêvão. A rua Dragão do Mar (Broadway), com seu portal, é uma atração à parte. Fotografar a igrejinha da vila, conhecer a lagoa do Oásis, a Duna da Tirolesa, considerada a mais alta de Canoa, o encontro do rio Jaguaribe com o mar e ver as enigmáticas formações rochosas de Ponta Grossa são atrativos obrigatórios de serem visto (sic) (ASDECQ 2013 p. 6)

\begin{abstract}
Logo ao chegar, respire fundo, sinta o clima de magia de Canoa Quebrada e relaxe, diversão é o que não falta nessa praia que encanta a todos que a visitam. Caminhe até as falésias, desça para a praia utilizando as escadas de madeira que facilitam o seu acesso. Escolha, entre tantas, uma barraca para almoçar e fique à vontade, a vida não tem pressa. Aceite a oferta de um aventureiro e tradicional passeio de jangadas à tarde, quando regressar ao vilarejo, o passeio de ultraleve é uma boa pedida, é fascinante ver Canoa do alto. Quando o sol começar a baixar no horizonte, é hora de ver um belo espetáculo da natureza, o pôr do sol de Canoa. Nessa hora, já é apropriado alugar um 'buggy' para te levar até a duna do Pôr do Sol, aproveite e faça um pacote com o 'bugueiro' para os passeios do dia seguinte. (Idem p. 8)
\end{abstract}

\section{Proteção ambiental}

Com trabalhos que iniciaram no final da década de 1980, foi instituída em 1997 através de lei municipal a Área de Preservação Ambiental e Paisagística da Zona Costeira do Município de Aracati, conhecida como APA de Canoa Quebrada. No ano seguinte foi criada a Área de Relevante Interesse Ecológico do Estêvão, com 200 ha. O território da APA de Canoa Quebrada "compreende trecho da faixa litorânea do município, incluindo falésias, duas móveis e fixas, mangue, mananciais e lagoas, além dos povoados de Canoa Quebrada, Estêvão, Canavieira, Cumbe e Beirada. " totalizando 6.340 ha e com perímetro de $38.139 \mathrm{~m}$ (DANTAS Op. cit.) 


\section{ANAP

Foram feitas observações durante visitas às localidades de Canoa Quebrada e Majorlândia durante o mês de julho de 2015. A tônica utilizada foi da percepção pelo olhar do turista sobre a infraestrutura disponível nestas localidades.

\section{Canoa Quebrada}

O principal destino turístico da região tem sua estrutura polarizada em torno da avenida principal, Av. Dragão do Mar, popularmente conhecida como "Broadway de Canoa Quebrada". Foi realizada pelo poder público uma requalificação dos espaços livres públicos desta via, transformada em calçadão para pedestres, com piso desenhado com a identidade visual da localidade, mobiliário urbano sofisticado - bancos, floreiras, pergulados e iluminação por led. O logradouro concentra os estabelecimentos comerciais mais sofisticados do local, muitos com nomes que remetem a localidades internacionais que por vezes denunciam a origem do proprietário, estrangeiro.

Figura 4. Estabelecimentos utilizam nomes e referências internacionais. Rua principal de Canoa Quebrada.

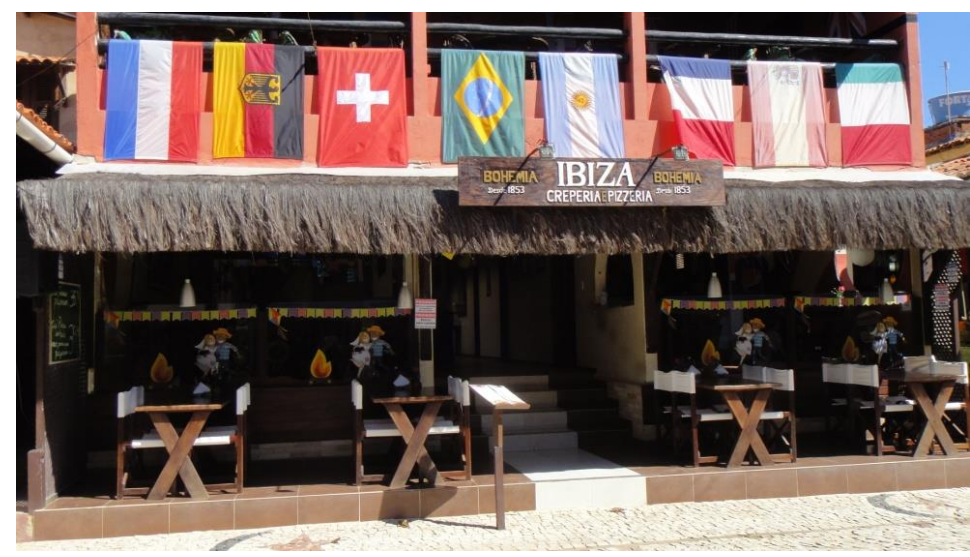

Fonte: Roberto Sakamoto 2015.

Para MASCARENHAS, turistas elegem as cidades turísticas como locais para a realização de seus desejos, "convertendo-se em aglomerações sazonais de serviços e artigos de prazer, voltados para uma clientela externa." A atividade proporciona a ascensão de pequenos capitais, favorecendo a 


\section{ANAP

formação de uma nova elite local. Esta elite constitui os segmentos sociais que lideram o debate político local. (MASCARENHAS apud KOROSSY 2012).

O resultado é a concentração dos turistas juntamente com moradores e trabalhadores configurando um espaço público vivo e funcional. A disposição dos bancos, vitrines, páteos e mesas de bares e restaurantes convidam ao conviver, parar, permanecer, olhar o movimento.

Figura 5. Rua principal de Canoa Quebrada reúne atributos de espaço público qualificado e adequado à escala do pedestre, atraindo as pessoas que utilizam os espaços intensamente dia e noite.
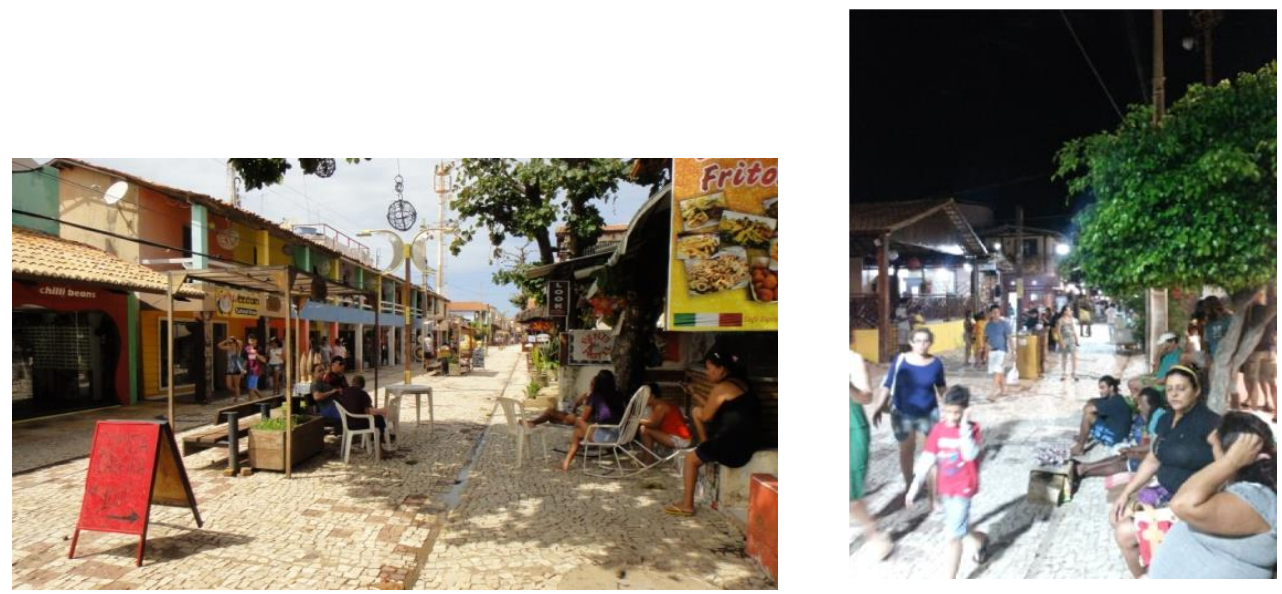

Fonte: Roberto Sakamoto 2015.

A qualidade do espaço urbano vem do fato de as pessoas utilizarem esses espaços. O seu sucesso depende deste poder de provocar nas pessoas a vontade de utilizá-los. Para GEHL,

Cidades convidativas devem ter um espaço público cuidadosamente projetado para sustentar os processos que reforçam a vida urbana. (...) Naturalmente, as pessoas se inspiram e são atraídas pela atividade e presença de outras pessoas. (...) Observar a vida na cidade é uma das mais importantes atrações urbanas. Ver gente é uma atividade universal que ocorre constantemente quando andamos, paramos ou sentamos. (...) A vida na cidade é um processo de autoalimentação, de autorreforço. Algo acontece porque algo acontece porque algo acontece. (GEHL 2014 p. 65 e 148) 


\section{ANAP

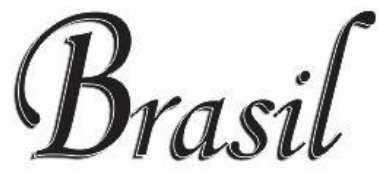 \\ ISSN 1904-3240 \\ V. 8, n. 11}

\section{REVISTA CIENTIFICA 2015}

Figura 6. "Após iniciada, uma brincadeira de criança pode, rapidamente, atrair mais participantes. Processos similares ocorrem com atividades de adultos. As pessoas vão a onde o povo está." (GEHL 2014 p. 64)
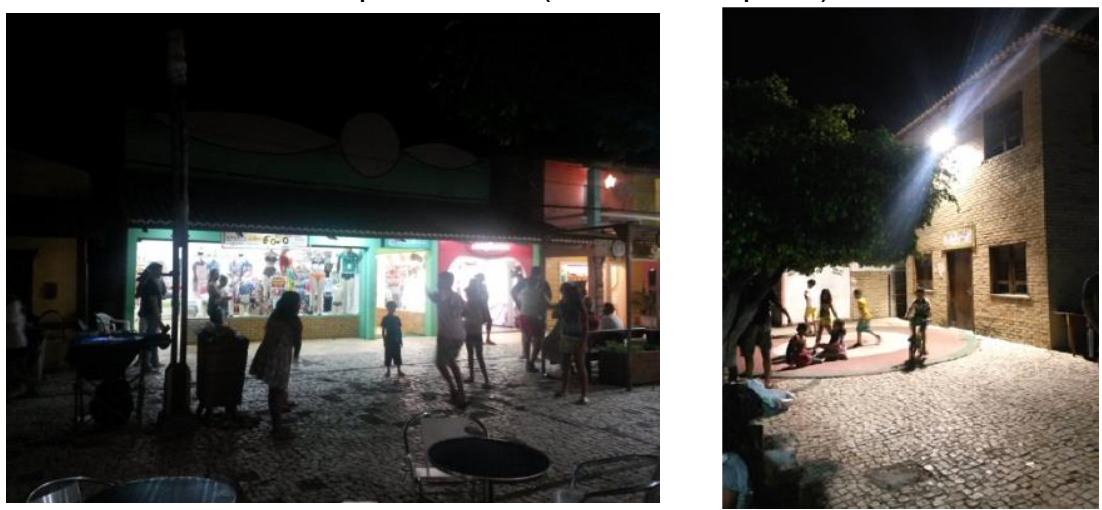

Fonte: Roberto Sakamoto 2015.

Conforme nos afastamos da rua principal, é possível observar um gradiente no qual o padrão de sofisticação da infraestrutura diminui conforme aumenta a distância desta. A começar pela coleta de esgoto, existente apenas nesta rua e em poucas outras - é possível notar pela presença ou ausência das tampas de inspeção com a inscrição "esgoto". Além do saneamento, decresce a sofisticação do pavimento, que se torna mais simples, depois desaparece. No arruamento tradicional, ruas estreitas com construções sem acabamento seriam denominadas como favelas em outro contexto.

Figura 7 -à esquerda.. Viela transversal à rua principal em Canoa Quebrada ainda possui tratamento sofisticado, com piso em mosaico português.

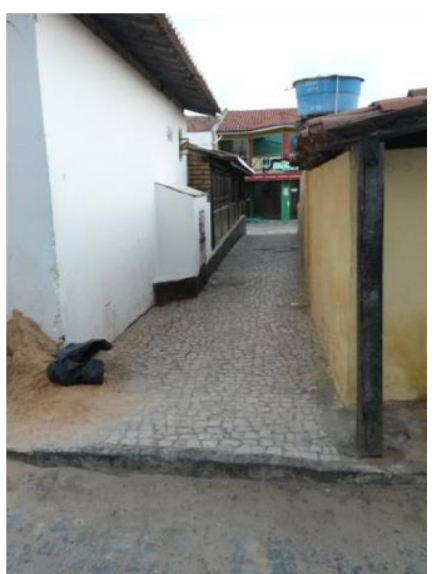

Fonte: Roberto Sakamoto 2015. 


\section{ANAP

Figura 8 - à direita. Travessa a duas quadras da rua principal em Canoa Quebrada com piso de areia e construções improvisadas. Local seria considerado precário e favelizado em outro contexto. Foto R. Sakamoto 2015.

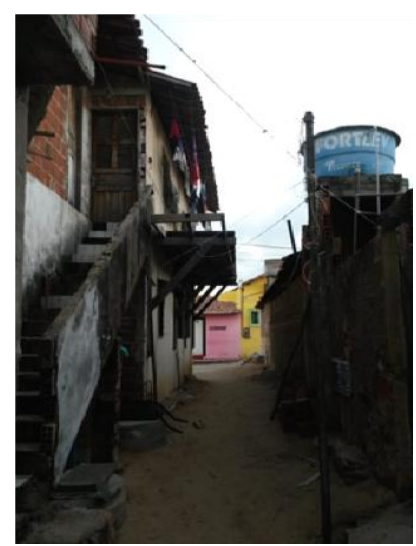

Fonte: Roberto Sakamoto 2015.

Majorlândia

Distante cerca de $4 \mathrm{~km}$ de Canoa Quebrada pela orla, ou $11 \mathrm{~km}$ por rodovia, Majorlândia é uma localidade próxima, com características geomorfológicas e paisagísticas muito semelhantes a Canoa Quebrada. O nome da localidade deriva de seu antigo proprietário, prefeito de Aracati na década de 1920 e conhecido pelo apelido de "Major".

Em levantamento da Secretaria de Turismo do Ceará, são descritos o “ potencial e capacidade atual" de Majorlândia. Aparentemente o levantamento se originou de visita única à localidade, sem ter havido consulta ou elaboração de pesquisa mais aprofundada.

Figura 9. Aspecto da orla de Majorlândia.

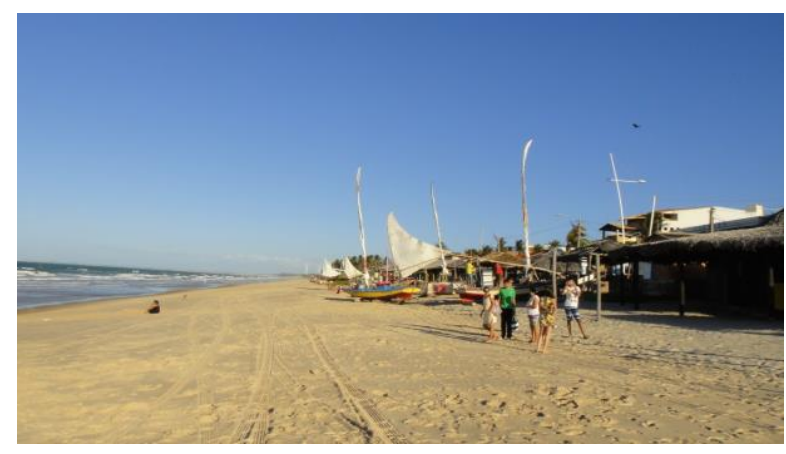

Fonte: Roberto Sakamoto 2015. 


\section{ANAP

O Plano de Desenvolvimento Integrado do Turismo Sustentável PDITS descreve os atrativos das praias de Majorlândia e de Canoa Quebrada de maneira muito distinta, apesar de geomorfologicamente e paisagísticamente serem muito semelhantes.

"Praia com ondas de médias para fortes, Majorlândia tem uma extensa faixa de areia, parte dela batida. Tem falésias brancas e vermelhas e coqueiros. Bastante movimentada aos finais de semana."

"A praia de Canoa Quebrada é internacionalmente conhecida pelas suas águas esverdeadas e por suas falésias coloridas, de onde sai a areia para a produção das famosas garrafinhas coloridas."

Figura 10. Aspecto da orla com falésias em Majorlândia.

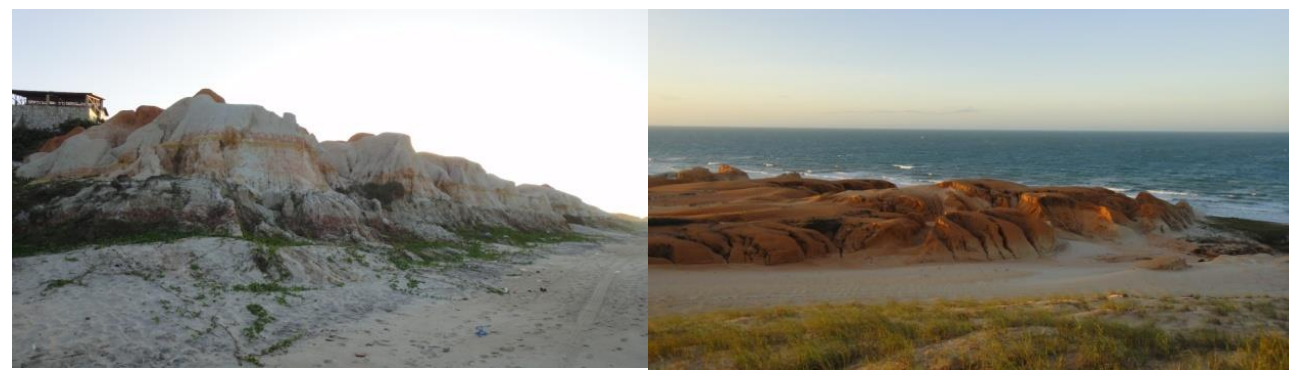

Fonte: Roberto Sakamoto, 2015.

Figura 11. Aspecto da orla com falésias em Canoa Quebrada.
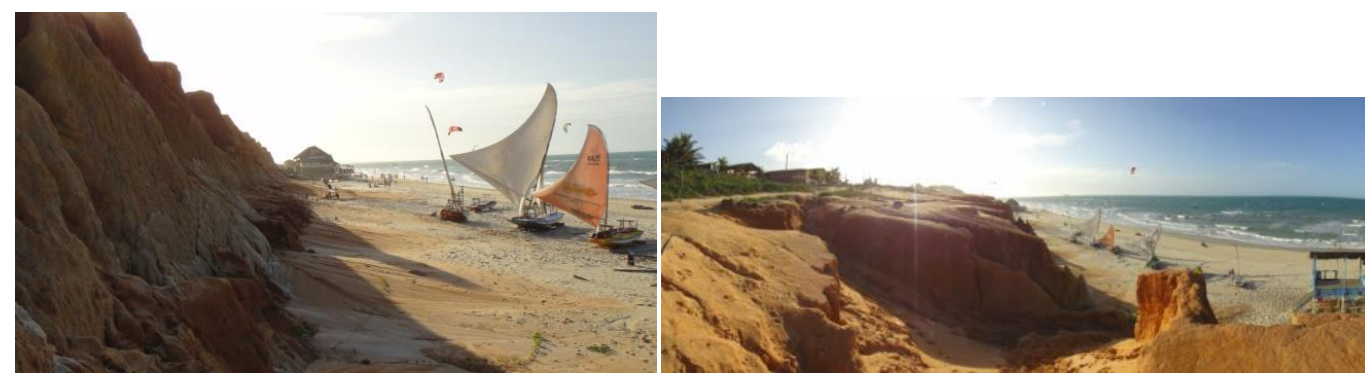

Fonte: Roberto Sakamoto, 2015.

\section{CONCLUSÃO}

O que fez de Canoa Quebrada o local escolhido pelos turistas? Seus atributos de beleza natural são exuberantes, porém não são exclusivos nem 


\section{ANAP $B_{\text {rasil }}$}

significativamente diferentes das localidades do entorno. A construção da rodovia, as obras de infraestrutura, os melhoramentos urbanos, surgiram em função desta demanda inicial, e não o contrário. Teria o nome da localidade influenciado no interesse inicial da comunidade hippie que a "descobriu"? Seria obra do acaso o fato de Canoa Quebrada ter desenvolvido o potencial turístico e Majorlândia não?

O que parece evidente é que não foram apenas os atributos naturais, cênicos e paisagísticos que tornaram Canoa Quebrada um destino turístico tão procurado. Tampouco foram os investimentos em infraestrutura e melhoramentos urbanos, pois que estes chegaram posterior e tardiamente ao processo de turistificação.

Canoa Quebrada reúne um conjunto de atributos que satisfazem aos desejos e demandas do turismo de massa, utilizando e vendendo a imagem de local rústico e idealizado que possuía antes do processo de turistificação. Tal processo ocasionou diversos problemas e ocorreu de forma semelhante a outras localidades do litoral brasileiro.

Percebemos uma lacuna no que se refere a informação para planejamento de ações turísticas nas localidades pesquisadas. As deficiências encontradas são sintomáticas em todas as esferas de governo. Observa-se em algumas publicações oficiais pouca consistência com relação às fontes de pesquisa e metodologias utilizadas. $O$ uso de expressões e informações de origem não informada é frequente, de onde se pode deduzir que há pouca oferta de informação, pesquisas e dados estatísticos recentes sobre o turismo regional disponíveis ${ }^{3}$. Na esfera federal, em uma consulta ao endereço eletrônico do Ministério do Turismo - dados e fatos em julho de 2015 é possível constatar defasagem de informação, onde as notícias mais recentes datam de mais de um ano atrás, fazendo referência à copa do mundo de 2014. O

\footnotetext{
${ }^{3}$ Nos documentos produzidos pela Secretaria de Turismo do Estado do Ceará - SETUR, como o Manual de operações do Programa de Desenvolvimento do Turismo - Prodetur Ceará ("Um dos lugares mais visitados por turistas do mundo inteiro (...) p. 53
} 


\section{ANAP

"Documento Referencial Turismo no Brasil" data de 2010 e possui informações desatualizadas no tocante, por exemplo, à conjuntura econômica do país e à infraestrutura existente.

Para GEHL, só podemos planejar assuntos os quais tenhamos disponíveis dados e estudos em quantidade e qualidade suficientes (GEHL op. cit.). Para YÁZIGI, a reconstrução do lugar deve ser vertebrada por seu habitante e, eventualmente, ser convertida em lugar turístico (YÁZIGI 2002 p. 281).

Neste sentido, faz-se necessário um maior investimento no que tange à organização e elaboração de dados relevantes sobre as questões que envolvem o planejamento turístico, paisagístico e urbanístico da região, de modo a subsidiar ações e investimentos que permitam conduzir o desenvolvimento econômico, social e ambiental destas localidades.

\section{REFERÊNCIAS BIBLIOGRÁFICAS}

ASDECQ - Associação dos Empreendedores de Canoa Quebrada. Revista Q Canoa ano 1, n. 1. Aracati: ASDECQ, 2013.

BRASIL. Ministério do Turismo. Estatísticas básicas de turismo 2013. Brasília: Ministério do Turismo, 2014.

Avaliação do Programa de Regionalização do Turismo - Roteiros do Brasil. Resumo Executivo. Brasilia: Ministério do Turismo, sem data.

CORBIN, Alain. O território do vazio. A praia e o imaginário ocidental. São Paulo: Companhia das Letras, 1989.

COSTA, Márcio Antônio Leal. GÂNDARA, José Manoel Gonçalves. Análise do plano estratégico de turismo (PET) de Ilhéus In: ÁVILA, Marco Aurélio (org.) Política e planejamento em cultura e turismo. Ilhéus: Editus, 2009 232p. (p. 99-126)

DANTAS, Shirley Carvalho. Turismo, produção e apropriação do espaço e percepção ambiental: o caso de Canoa Quebrada, Aracati, Ceará. Dissertação de mestrado. Programa de pós graduação em Desenvolvimento e Meio Ambiente. Área de concentração Ecologia e organização do espaço. Fortaleza: Universidade Federal do Ceará, 2003.

GEHL, Jan. Cidades para pessoas. São Paulo: Perspectiva, 2014.

KOROSSY, Nathália. Turismo, território e espaço urbano: considerações sobre o processo de turistificação e urbanização turística. In: CASTILHO, Cláudio J. M. e SELVA, 


\section{ANAP

Vanice S. F. Turismo, políticas públicas e gestão dos ambientes construídos. Recife: Universitária, UFPE, 2012.

MACHADO, Helena Cristina F. A Construção Social da Praia. In: Sociedade e Cultura I, Cadernos do Noroeste, Série Sociologia, vol 13. Braga: Universidade do Minho, 2000 p. 201 218.

MACEDO, Silvio Soares. Paisagem, urbanização e litoral: do éden à cidade. Tese de Livre Docência. São Paulo: FAUUSP, 1993.

NÓBREGA, Wilker Ricardo de Mendonça. As novas territorialidades decorrentes da atividade turística: o caso do distrito de Mosqueiro, Belém do Pará (p. 127-154) In: ÁVILA, Marco Aurélio (org.) Política e planejamento em cultura e turismo. Ilhéus: Editus, 2009 232p.

SENA, Maria de Fátima Alves. QUEIROZ, Odaléia Telles Marcondes Machado. Impactos ambientais e sócio-culturais do turismo de segunda residência: o caso do povoado de Ponta da Tulha, Ilhéus, BA. (p. 155-180) In: ÁVILA, Marco Aurélio (org.) Política e planejamento em cultura e turismo. Ilhéus: Editus, 2009 232p.

SETUR - Secretaria de Turismo do Estado do Ceará. Estudos de mercado dos polos turísticos do PRODETUR Nacional no Estado do Ceará, Produto 3 - Estudo de Demanda Atual. Fortaleza: IPETURIS, 2011.

Estudos de mercado dos polos turísticos do PRODETUR Nacional no Estado do Ceará, Produto 5 - Análise da Oferta Turística, Volume I - Polo Litoral Leste. Fortaleza: IPETURIS, 2011.

Indicadores turísticos 1995/2013. Fortaleza: SETUR, 2014.

Plano de Desenvolvimento Integrado do Turismo Sustentável - PDITS - polo Litoral Leste. Tomos I e II. Fortaleza: SETUR, 2014.

YÁZIGI, Eduardo. A Alma do Lugar. Turismo, Planejamento e Cotidiano. São Paulo: Contexto, 2002.

http://g1.globo.com/ceara/noticia/2014/05/anac-autoriza-voos-comerciais-no-aeroporto-dearacati-no-ceara.html acesso em 1-jul-2015

http://www.aracati.ce.gov.br/aeroporto-dragao-do-mar-em-aracati-e-homologado-pela-anac/ acesso em 1-jul-2015

http://www.dadosefatos.turismo.gov.br/dadosefatos/estatisticas_indicadores/downloads_estatist icas/Estatisticas_Basicas_do_Turismo_Brasil_2008_2013_Agosto_2014.xIsx acesso em 1-jul2015

http://historiasdoaracati.blogspot.com.br/2011/12/o-major-e-majorlandia.html acesso em 1-jul2015 